\title{
Correlation between quality of life and disease severity of pediatric patients with atopic dermatitis
}

\author{
MARA SUR $^{1 *}$, ANDREEA NICOLETA BOCA ${ }^{2 *}$, ROXANA FLAVIA ILIES ${ }^{3 *}$, \\ EMANUELA FLOCA ${ }^{4}$, ALEXANDRU TATARU ${ }^{1}$ and LUCIA SUR ${ }^{4}$

\begin{abstract}
Departments of ${ }^{1}$ Dermatology, ${ }^{2}$ Pharmacology, Toxicology and Clinical Pharmacology, ${ }^{3}$ Medical Genetics and ${ }^{4}$ Pediatrics, 'Iuliu Hatieganu' University of Medicine and Pharmacy, 400012 Cluj-Napoca, Romania
\end{abstract}

Received July 8, 2020; Accepted August 7, 2020

DOI: $10.3892 / \mathrm{etm} .2020 .9319$

\begin{abstract}
Atopic dermatitis (AD) is a complex, chronic skin disorder with a broad spectrum of clinical aspects, characterized by abnormal skin barrier function. This has a significant impact on patients' quality of life $(\mathrm{QoL})$, which represents a crucial parameter for their wellbeing. This study assessed the QoL of patients with AD by following parameters such as itching, disturbance of sleep, disturbance of play activity, and community activities. The study included 64 patients clinically diagnosed with $\mathrm{AD}$, aged 0 to 16 years. QoL of patients with $\mathrm{AD}$ was measured by evaluating the QoL indices for infants and young children (IDQoL-Infants' Dermatitis Quality of Life Index) and the QoL for children over 4 years (CDQoL-Children's Dermatology Life Quality Index). The severity of the disease was also monitored by evaluating the SCORAD index. The major symptom for atopic dermatitis, pruritus, was found most frequently in our study and influenced patients' QoL. The study showed that the above questionnaires are efficient tools for correlating AD severity with QoL even in younger patients and could be included in current guidelines. This is the first study that analyzed the QoL of pediatric patients with atopic dermatitis in Romania and can constitute the basis for elaborating a more comprehensive disease management guidelines.
\end{abstract}

Correspondence to: Dr Andreea Nicoleta Boca, Department of Pharmacology, Toxicology and Clinical Pharmacology, 'Iuliu Hatieganu' University of Medicine and Pharmacy, 23 Marinescu Street, 400012 Cluj-Napoca, Romania

E-mail: boca.andreea@umfcluj.ro

${ }^{*}$ Contributed equally

Abbreviations: AD, atopic dermatitis; QoL, Quality of life; SCORAD, SCORing Atopic Dermatitis; DLQI, Dermatology Life Quality Index; HRQoL, Health Related Quality of Life; IDQoL, Infants' Dermatitis Quality of Life Index; CDQoL, Children's Dermatology Life Quality Index

Key words: atopic dermatitis, quality of life, severity, pediatric patients, SCORAD, IDQoL, CDQoL

\section{Introduction}

Atopic dermatitis (AD) is a complex inflammatory skin disease with different clinical aspects. This pathology affects $20 \%$ of children and $3 \%$ of adults. Several mechanisms have been described to determine AD: These mechanisms include dysfunction of the immune system with $\mathrm{Th} 2$ predominance with IL4, IL5, and IL13 production, associated with increased $\mathrm{IgE}$ and decreased gamma interferon. Another mechanism implicated in DA is the dysfunction of the epidermal barrier. By disrupting this barrier, antigens can penetrate the skin and generate the production of inflammatory cytokines that support the underlying mechanism of the pathology (1).

Quality of life (QoL) is a crucial parameter for the patient's health, also representing an essential indicator in the follow-up of patients with atopic dermatitis. Characterized by an unpredictable evolution, $\mathrm{AD}$ evolves from mild forms, when the manifestations affect only the patient's appearance to severe forms that require treatment by a multidisciplinary team. Fortunately, most cases in children are mild forms, but in some cases, they may present symptoms of aggravation (2).

AD typically starts around the age of 2 months, but there are cases when the symptoms manifest later. Essential for the assessment of the disease evolution is the follow-up of daily activity, sleep, itching, and in more severe cases of depressive manifestations. Although at first sight, AD appears to be a mild disease, the diagnosis and treatment must be made by specialists in allergic diseases with a thorough knowledge of physiology, pathophysiology, and pharmacology (3). Anamnesis and clinical examination were the only ways of assessing the QoL in patients with $\mathrm{AD}$, even though other methods have been elaborated to allow a more objective assessment. These include the appreciation of sleep, itching and daily activities.

Several tools can be used to assess the QoL: These include HRQoL (Health Related Quality of Life). This tool is multidimensional and analyzes different aspects of life, such as mental, emotional, and social aspects. The questionnaires for HRQoL analyze the intensity of the symptoms and their frequency. The Dermatology Quality Life Index (DLQI) is the most utilized in dermatology, analyzing such items as the weekly itching, pain and inflammation. There are also similar questionnaires, such as Patient-Oriented Eczema Measure 
(POEM), that analyze weekly symptoms as well as their daily changes (4).

The age of the patient also influences the QoL of patients with AD. It has been found that the highest prevalence of the disease is found in children, about $20 \%$, and consequently, the disturbance of QoL is higher in children (5). The QoL is mainly influenced by the severity of $\mathrm{AD}$, and affecting moderate and severe forms rather than mild forms. As AD is increasing, early recognition of the manifestations and prompt implementation of therapeutical measures can limit the consequences of the disease. Far from an acute disease, AD is a chronic inflammatory pathology, with phases of remission and exacerbation which are impacted by nutritional, environmental and psycho-emotional factors.

This study assessed the QoL of patients with AD. This can be assessed by parameters such as itching, disturbance of sleep, disturbance of play activity, and community activities. QoL of patients with AD was assessed by evaluating the QoL indices for infants and young children (IDQoL-Infants' Dermatitis Quality of Life Index) and the QoL for children over 4 years (CDQoL-Children's Dermatology Life Quality Index). The severity of the disease was also monitored by evaluating the SCORAD index (6).

\section{Patients and methods}

Participants. The study is an observational analytical study performed in the 2nd Pediatrics Clinic Department, Cluj-Napoca, Romania between January 2018 and June 2019. In total, 64 patients aged 0 to 16 years were included in the study. The inclusion criteria were the following: Age 3 months to 16 years and the presence of skin lesions typical for AD at the beginning of the study. The major diagnostic criteria is itching. The minor criteria include the following: History of flexural lesions (elbow, popliteal fossa, perimaleolar region, laterocervical region); personal history of asthma or rhinitis (or history of atopic disease in first-degree relatives in children $<4$ years); history of xerotic skin in the previous year, onset of symptoms under 2 years of age (this criterion is not valid in children $<4$ years); lesions that affect the flexural areas and for children $<4$ years old-lesions on the forehead and cheeks. For AD diagnosis, the patient must present the major criteria and 3 or more minor criteria. The exclusion criteria in the study were the following: Acute infectious diseases, autoimmune diseases, skin manifestations of other diseases, lack of informed consent.

The main group was divided into 3 smaller groups according to age: 3 months to 4, 5-9, and 10-16 years. We used the existent questionnaires, that include 10 questions adapted to age, and language concerning the QoL. The parents answered the questionnaire for the 3 months to 4 years age group. We evaluated the pruritus, sleep disorders, sleep duration, mood, play intervals, family activities, nutrition, treatment, bathing program, and dressing. In the 5-9 years and 10-16 years age groups, the questions referred to itching, activity, dressing, friends, leisure, sports such as swimming, school activities, sleep, bullying behavior and treatment. In these age groups, the questionnaires were completed by children and parents.

The study was approved by the Ethics Committee of 'Iuliu Hatieganu' University of Medicine and Pharmacy
(Cluj-Napoca, Romania), and written informed consent was obtained from the parents or legal guardians of the children.

Clinical evaluation. Each question for evaluating the QoL was scored from 0 to 3. 0 , indicates lack of manifestations, 1 , mild manifestations, 2, moderate manifestations, and 3, severe manifestations. The maximum score obtained in the questionnaire is 30 points. The patients were evaluated concerning the severity of AD using the SCORAD index. The objective SCORAD index evaluates the presence and severity of the lesions (erythema, edema, crusts, scoria, lesions of lichenification, skin xerosis) as well as the assessment of the pruritus intensity and sleep disorders on a scale from 1 to 10 . Depending on the score obtained, AD is classified into severity forms: $<15$ mild form, 15-40 moderate form and $>40$ severe form.

Statistical analysis. Continuous variables were expressed by standard deviation and categorical variables by frequency and percentage. For assessing differences between the variables, the Student test and the Kruskal-Wallis test were used. The correlation between IDQoL and CDLQI scores and AD severity (SCORAD index) was evaluated using Pearson correlation coefficients. Multiple linear regression analysis was used to determine the age link of the IDQoL and CDLQI scores. The dependent variables were the IDQoL and CDLQI scores. The independent variables in all models were age, sex, presence of atopic disease, family history of atopy, and severity of the disease. $\mathrm{P}<0.05$ was considered as statistically significant. All statistical analyzes were performed with Statistical Package for the Social Sciences (SPSS), version 20.0 for Windows.

\section{Results}

Study group characteristics. The study included 64 patients aged from 0 to 16 years. The evaluated parameters of the patients included in the study according to age are shown in Table I. The cases were divided into 3 different age groups: 0-4 years (with a mean age of 1.94 years), 5-9 years (with a mean age of 7.08 years) and 10-16 years (with a mean age of 13.12 years). In the 3 months to 4 years group the predominant gender was male, representing $60.9 \%$, and the females were $39.1 \%$. In the further two age groups, the ratio of female to male patients was $50 / 50 \%$. The 3 age groups did not differ significantly according to gender. Analyzing the associations with other diseases, we found statistically significant differences, regarding the presence of the associated atopic diseases and the severity of AD. The association of concomitant allergic diseases was more common in children from groups 5-9 and 10-16 years, than in the youngest group. The severity score, estimated with the help of the SCORAD index, was higher in the age groups 5-9 and 10-16 years. The most widespread form, according to severity was the mild form $(54.7 \%)$, followed by the moderate form (35.9\%) and the severe form (9.4\%). The severe form was found with predilection in patients over 5 years of age.

QoL assessment. In order to assess the QoL, several parameters were analyzed, both at younger and older ages, illustrated 
Table I. Characteristics of the study group by age.

\begin{tabular}{|c|c|c|c|c|c|}
\hline Variables & All ages & $0-4$ years & $5-9$ years & $10-16$ years & P-value \\
\hline No. of patients & 64 & $44(68.7 \%)$ & $12(18.8 \%)$ & $8(12.5 \%)$ & \\
\hline Age $($ mean $\pm \mathrm{SD})$ & $7.38 \pm 4.18$ & $1.94 \pm 0.96$ & $7.08 \pm 1.38$ & $13.12 \pm 1.32$ & \\
\hline Sex & & & & & 0.184 \\
\hline Male & $39(60.9 \%)$ & $29(65.9 \%)$ & $6(50 \%)$ & $4(50 \%)$ & \\
\hline Female & $25(39.1 \%)$ & $15(34.1 \%)$ & $6(50 \%)$ & $4(50 \%)$ & \\
\hline Atopy & & & & & $<0.001$ \\
\hline Only Atopic Dermatitis & $28(43.8 \%)$ & $29(65.9 \%)$ & $4(33.3 \%)$ & $3(37.5 \%)$ & \\
\hline Atopic disease associated & $36(56.2 \%)$ & $15(34.1 \%)$ & $8(66.7 \%)$ & $5(62.5 \%)$ & \\
\hline SCORAD index & & & & & 0.002 \\
\hline Mild & $35(54.7 \%)$ & $35(79.5 \%)$ & 0 & 0 & \\
\hline Moderate & $23(35.9 \%)$ & $8(18.2 \%)$ & $10(83.3 \%)$ & $5(62.5 \%)$ & \\
\hline Severe & $6(9.4 \%)$ & $1(2.3 \%)$ & $2(16.7 \%)$ & $3(37.5 \%)$ & \\
\hline SCORAD index (mean value) & $21.4 \pm 10.4$ & $16.4 \pm 10.9$ & $21.4 \pm 9.8$ & $20.9 \pm 10.6$ & \\
\hline
\end{tabular}

Table II. Quality of life of patients with atopic dermatitis by age.

\begin{tabular}{|c|c|c|c|c|c|}
\hline \multicolumn{2}{|c|}{ IDQOL } & \multicolumn{4}{|c|}{ CDLQI } \\
\hline Parameter & $\begin{array}{c}0-4 \text { years } \\
\text { Mean } \pm \text { SD }\end{array}$ & Parameter & $\begin{array}{c}5-9 \text { years } \\
\text { Mean } \pm \text { SD }\end{array}$ & $\begin{array}{l}10-16 \text { years } \\
\text { Mean } \pm S D\end{array}$ & P-value \\
\hline Itch & $1.39 \pm 0.82$ & Itch & $2.19 \pm 0.62$ & $1.43 \pm 0.69$ & $<0.015$ \\
\hline Mood change & $1.85 \pm 0.79$ & Embarrassing situations & $1.78 \pm 1.03$ & $1.51 \pm 1.15$ & 0.261 \\
\hline Sleep duration & $1.30 \pm 0.85$ & Friends & $2.03 \pm 0.85$ & $1.85 \pm 0.82$ & 0.258 \\
\hline Sleeping disturbance & $1.10 \pm 0.81$ & Clothes/Shoes & $1.76 \pm 0.79$ & $1.51 \pm 0.94$ & 0.123 \\
\hline Play & $1.40 \pm 0.80$ & Free time/hobbies & $2.20 \pm 0.75$ & $1.83 \pm 0.85$ & 0.034 \\
\hline Family activities & $1.45 \pm 0.88$ & Swimming/sport & $2.10 \pm 0.82$ & $1.45 \pm 1.09$ & $<0.001$ \\
\hline Food & $1.42 \pm 0.81$ & Șchool/holiday & $2.40 \pm 0.65$ & $2.20 \pm 0.62$ & 0.109 \\
\hline Treatment & $1.69 \pm 0.86$ & Teasing/intimidation & $1.91 \pm 0.73$ & $1.64 \pm 0.83$ & 0.021 \\
\hline Bandage & $1.35 \pm 0.85$ & Sleep & $1.45 \pm 0.65$ & $1.16 \pm 0.85$ & 0.027 \\
\hline Bathroom schedule & $1.41 \pm 0.89$ & Treatment & $1.48 \pm 0.74$ & $1.23 \pm 0.74$ & 0.187 \\
\hline
\end{tabular}

IDQOL-Child Quality Index of Young Children with Dermatitis; CDLQI-Dermatological Index of the Quality of Life of the older Child with atopic dermatitis.

in Table II. The highest IDQOL scores were found in pruritus, child's disposition, and treatment problems. The lowest scores were related to sleep disturbance and the time needed to fall asleep. In older children, the QoL assessed by CDLQI, in both age groups, the highest scores were related to problems during school, holidays and pruritus. The lowest scores for these age groups were obtained on questions related to sleep and treatment. The significant difference between the 2 groups, respectively 5-9 and 10-16 years, was obtained concerning the swimming questions. At this question, the highest QoL deficiency was obtained in children aged 5-9 years. Other significant elements between the 2 groups would be questions about teasing, intimidation, sleep problems and hobbies. These questions had higher values in children aged 5-9 years compared with those in the group of 10-16 years.
Table III. Correlation between quality of life (IDQOL/CDLQI) and severity of atopic dermatitis (SCORAD), according to age groups.

\begin{tabular}{lccccc}
\hline Age groups & $\begin{array}{c}0-4 \\
\text { years }\end{array}$ & $\begin{array}{c}5-9 \\
\text { years }\end{array}$ & $\begin{array}{c}10-16 \\
\text { years }\end{array}$ & $\begin{array}{c}5-16 \\
\text { years }\end{array}$ & All ages \\
\hline $\begin{array}{l}\text { Pearson's correlation } \\
\text { coefficient }\end{array}$ & 0.59 & 0.89 & 0.43 & 0.52 & 0.57 \\
\hline
\end{tabular}

Correlations. The correlation between IDQOL, CDLQI, and the severity of AD, according to the SCORAD index, are presented in Table III. The most significant correlation between the parameters and the severity levels according to SCORAD 


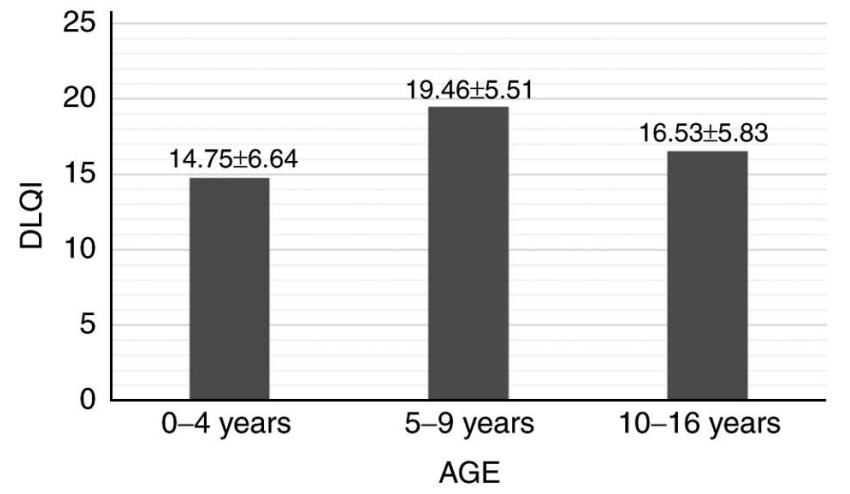

Figure 1. Quality of life scores by age groups. There was significant difference, $\mathrm{P}<0.001$, between the average total QOL score for the 3 age groups. Analyzing the scores by age group, the highest score was detected in children between 5 and 9 years $(19.46 \pm 5.51)$. The lowest score was recorded in the age group 0-4 years.

was identified in the age group 5-9 years, as seen in Fig. 1. The most significant correlation was observed between the CDLQI and SCORAD scores in the 5-9 years age group (0.89) and moderate correlation in the other 2 age groups $(0-4,0.59$ and $10-16$ years, 0.43$)$. There was also a moderate correlation between the CDLQI score and the SCORAD index, for the entire age range of 5-16 years.

\section{Discussion}

QoL represents the main goal for patients, parents, and physicians. The purpose of therapy is to augment the patients' QoL, thus offering the ability to normalize social interactions and activities for the patient. It is known that invisible diseases' are easier to bear psychologically than those that have an aesthetic impact (7). Most often, the psychological implications have an impact on the evolution of the disease, treatment, and can ultimately lead to social isolation and school dropout. It is precisely for this reason that diseases, such as atopic dermatitis, should be addressed, considering all the aspects that can cause an unfavorable evolution (8). Fortunately, in children, mild and moderate forms of the disease are the most frequent, but severe forms have a significant impact on the social integration of children. For the correct approach of patients with severe forms, teams of pediatric allergologists, dermatologists, psychiatrists and psychologists are needed (9-11).

Our study of AD QoL evaluation in pediatric patients is, to our knowledge, the first study of this kind undertaken in Romania. Analyzing comparatively the QoL by age groups, we found that the most affected was the group of 5-9 years (mean score was $19.46 \pm 5.5)$, followed closely by the group aged $10-16$ years (mean score was $16.53 \pm 5.83$ ). In the age group of $0-4$ years, the mean score was $14.75 \pm 6.64$. The study analyzed the correlations between IDQOL and CDLQI and the severity of atopic dermatitis evaluated by calculating the SCORAD index. The most significant correlation was observed in the group of 5-9 years, whose Pearson correlation coefficient was 0.89 . In the other two age groups, moderate correlations, respectively, at 0-4 years of 0.59 , and at 10-16 years of 0.43 were found. A moderate correlation was also found between
CDLQI and the SCORAD index in the age group 5-16 years, with a correlation coefficient of 0.57 .

Previous studies that analyzed a possible correlation between the age of the child and the QoL of the patient with AD were found in literature. The study of Campos et al (12) showed that the average CDLQI score was higher for younger children compared with older children. An international study by Chernyshov et al (13) revealed a significant correlation of CDLQI with children's age.

Not all parameters of QoL analyzed have similar effects on the patient's activity. In the young age groups, the most common symptoms were itching, child's disposition, and treatment. In older age groups, most problems were related to school attendance, vacations, itching, leisure, and hobbies.

Itching, defined as an unpleasant sensation that causes the desire to scratch, is a significant symptom of atopic dermatitis and other atopic diseases. Pruritus is the major diagnostic criterion in AD, and can severely affect the QoL of these patients. Itching had the highest score in all age groups and negatively impacted the QoL. The frequent need for scratching and grating of the lesions leads to nocturnal awakening, fatigue, and irritability (14-16).

Studies in other centers show that sleep can be disturbed in over $60 \%$ of cases, and during exacerbations in over $80 \%$. Our study confirmed these results. It is found that patients can lose about $2 \mathrm{~h}$ of sleep per night due to wakefulness caused by itching $(16,17)$. In our study, the QoL due to sleep disorders affected up to $50 \%$ of patients. The consequences of sleep deprivation are significant and may include mood swings, fatigue, and lack of concentration. These manifestations will ultimately affect school performance and social activities. The issue of sport had a greater impact on the age group 5-9 years in the studied group. School isolation, teasing, and intimidation led to the onset of depression, generating school absenteeism and social separation (18-21).

In conclusion, the present study showed significant correlation between the QoL and the manifestations of the severity of atopic dermatitis. These results encourage the creation of integrative therapy guidelines, aimed at improvement of clinical symptoms and QoL alike.

\section{Acknowledgements}

Not applicable.

\section{Funding}

No funding was received.

\section{Availability of data and materials}

The datasets used and/or analyzed during the present study are available from the corresponding author on reasonable request.

\section{Authors' contributions}

MS, LS and RFI were responsible for the acquisition and analysis of the data regarding the disease and the questionnaire parameters. EF, AT and ANB contributed to the conception and design of the study, and revised the manuscript critically 
for important intellectual content. MS, ANB and RFI contributed to the writing of the manuscript. All authors read and approved the final version of the manuscript.

\section{Ethics approval and consent to participate}

The study was approved by the Ethics Committee of 'Iuliu Hatieganu' University of Medicine and Pharmacy (Cluj-Napoca, Romania), and written informed consent was obtained from the parents or legal guardians of the children.

\section{Patient consent for publication}

Not applicable.

\section{Competing interests}

The authors declare that they have no competing interests.

\section{References}

1. Solomon I, Ilie M, Draghici C, Voiculescu VM, Căruntu C, Boda D and Zurac S: The impact of lifestyle factors on evolution of atopic dermatitis: An alternative approach (Review). Exp Ther Med 1078-1084, 2018.

2. Olsen JR, Gallacher J, Finlay AY, Piguet V and Francis NA: Quality of life impact of childhood skin conditions measured using the Children's Dermatology Life Quality Index (CDLQI) A meta-analysis. Br J Dermatol 174: 853-861, 2016.

3. Kage P, Simon J and Treudler R: Atopic dermatitis and psychosocial comorbidities. J Dtsch Dermatol Ges 18: 93-102, 2020.

4. Olsson M, Bajpai R, Yew YW, Koh MJA, Thng S, Car J and Järbrink K: Associations between health-related quality of life and health care costs among children with atopic dermatitis and their caregivers: A cross-sectional study. Pediatr Dermatol 37: 284-293, 2020

5. Holm J, Agner T, Clausen ML and Thomsen S: Quality of life and disease severity in patients with atopic dermatitis. J Eur Acad Dermatol Venereol 30: 1760-1767, 2016.

6. Ražnatović Đurović M, Janković J, Tomić Spirić V, Relić M, Sojević Timotijević Z, Ćirković A, Đurić S and Janković S: Does age influence the quality of life in children with atopic dermatitis? PLoS One 14: e0224618, 2019.

7. Xerfan EMS, Tomimori J, Andersen ML, Tufik S and Facina AS: Sleep disturbance and atopic dermatitis: A bidirectional relationship? Med Hypotheses 140: 109637, 2020.

8. Chernyshov PV: Stigmatization and self-perception in children with atopic dermatitis. Clin Cosmet Investig Dermatol 9: 159-166, 2016.
9. Xu X, van Galen LS, Koh MJA, Bajpai R, Thng S, Yew YW, Ho VPY, Alagappan U, Järbrink KSA and Car J: Factors influencing quality of life in children with atopic dermatitis and their caregivers: A cross-sectional study. Sci Rep 9: 15990, 2019

10. Gabes M, Chamlin SL, Lai J, Cella D, Mancini AJ and Apfelbacher CJ: Development of a validated short-form of the Childhood Atopic Dermatitis Impact Scale, the CADIS-SF15.J Eur Acad Dermatol Venereol: Mar 16, 2020 doi: 10.1111/jdv.16362. (Online ahead of print).

11. Gerbens LAA, Prinsen CAC, Chalmers JR, Drucker AM, von Kobyletzki LB, Limpens J, Nankervis H, Svensson A, Terwee CB, Zhang J, et al: Evaluation of the measurement properties of symptom measurement instruments for atopic eczema: A systematic review. Allergy Eur J Allergy Clin Immunol 72: 146-163, 2017.

12. Campos ALB, Araújo FM, Santos MALD, Santos AASD and Pires CAA: Impact of atopic dermatitis on the quality of life of pediatric patients and their guardians. Rev Paul Pediatr 35: 5-10, 2017.

13. Chernyshov PV, Ho RC, Monti F, Jirakova A, Velitchko SS, Hercogova $\mathrm{J}$ and Neri E: Gender differences in self-assessed health-related quality of life in children with atopic dermatitis. J Clin Aesthet Dermatol 9: 19-24, 2016.

14. Harrison IP and Spada F: Breaking the itch-scratch cycle: Topical options for the management of chronic cutaneous itch in atopic dermatitis. Medicines (Basel) 6: 76, 2019.

15. El Hachem M, Di Mauro G, Rotunno R, Giancristoforo S, De Ranieri C, Carlevaris CM, Verga MC and Dello Iacono I: Pruritus in pediatric patients with atopic dermatitis: A multidisciplinary approach - summary document from an Italian expert group. Ital J Pediatr 46: 11, 2020.

16. Yang EJ, Beck KM, Sekhon S, Bhutani T and Koo J: The impact of pediatric atopic dermatitis on families: A review. Pediatr Dermatol 36: 66-71, 2019.

17. Ramirez FD, Chen S, Langan SM, Prather AA, McCulloch CE, Kidd SA, Cabana MD, Chren MM and Abuabara K: Association of atopic dermatitis with sleep quality in children. JAMA Pediatr 173: e190025, 2019

18. Bonamonte D, Filoni A, Vestita M, Romita P, Foti C and Angelini G: The role of the environmental risk factors in the pathogenesis and clinical outcome of atopic dermatitis. Biomed Res Int 2019: 2450605, 2019.

19. Na CH, Chung J and Simpson EL: Quality of life and disease impact of atopic dermatitis and psoriasis on children and their families. Children (Basel) 6: 133, 2019.

20. Maksimovic N, Zaric M, Reljic V, Nikolic M and Gazibara T: Factors associated with improvement of quality of life among parents of children with atopic dermatitis: 1-year prospective cohort study. J Eur Acad Dermatology Venereol 34: 325-332, 2020.

21. Al-Afif KAM, Buraik MA, Buddenkotte J, Mounir M, Gerber R, Ahmed HM, Tallman AM and Steinhoff M: Understanding the burden of atopic dermatitis in Africa and the Middle East. Dermatol Ther (Heidelb) 9: 223-241, 2019. 